\title{
Does Medicine Need Liaison Psychiatry?
}

\author{
C. J. Thомаs, Consultant Liaison Psychiatrist, Leicester General Hospital
}

In February 1984 at the Quarterly Meeting of the Royal College of Psychiatrists, Professor A. Guz from the Department of Medicine, Charing Cross Hospital, presented a paper with the above title. In this paper he raised a number of points regarding the role of liaison psychiatry and of the psychiatrists involved in practising it. The paper collated the views of himself and other professors of medicine, and obviously it is important that we as psychiatrists take note of the opinions expressed by people with such an extensive knowledge of medicine. Many of the points which Professor Guz raised I found myself to be in total agreement with; however, there were one or two issues which I think perhaps deserve a reply and I would like to attempt to do this through the Bulletin. As many of the Bulletin readers will know, there is an increasing interest in liaison psychiatry and this has been recognized by the College in the recent establishment of a special interest group. I should perhaps point out, however, that the views expressed in this article are mine alone and do not necessarily represent those of any other liaison psychiatrist, or of the special interest group.

Professor Guz felt that it was important that liaison psychiatrists should have obtained postgraduate experience in medicine, perhaps even have obtained the MRCP. It would certainly appear to be a very sensible suggestion that any psychiatrist intending to specialize in the liaison field should try to obtain further experience in general medicine before entering psychiatry. To do this would require the potential psychiatric trainee obtaining SHO posts in medicine after their registration year. I imagine it would be difficult to envisage many physicians giving up a six or twelve-month post-registration job to a doctor whose main training was to be in psychiatry. Most medical SHO jobs are very well sought after and understandably those applicants who seem best suited to a successful career in medicine itself will be accepted, and it is likely that any doctor who applied for such a job and who honestly stated that after six months or a year he would be leaving to do psychiatry would probably never be a successful applicant. It is therefore difficult to see how psychiatrists nowadays may obtain further medical experience. It has been suggested that such experience could be gained by psychiatric trainees attending various medical ward rounds and postgraduate meetings during their time on a psychiatric rota. Again, however, this is never easy as their own training and clinical commitments will make such arrangements liable to be very haphazard and I am sure most physicians would agree that proper experience could only be obtained by being in a post full-time. One solution perhaps would be to allocate specific time during psychiatric rotation for trainees to be allowed to act as supernumerary SHOs in medical firms for periods of two to three months. Professor Guz felt that psychiatrists should 'know the brain' and periods of attachment to neurology firms during their training would allow psychiatrists a chance to achieve this. I think that if physicians are serious in their request that psychiatrists should have further experience then perhaps the two respective colleges need to jointly consider the best method for achieving this.

Another point Professor Guz raised was a feeling that medicine only required a small number of specialized liaison psychiatrists. Currently there are only a few psychiatrists who devote a major part of their time to liaison work and with the present economic situation it is probable that further expansion at the consultant level will not be great. I feel strongly, however, that whereas it would be wrong to divert existing posts in psychiatry into liaison posts, it is essential that more psychiatrists should obtain some training in this field. With the proposed development of more DGH psychiatric units it is probable that more and more general psychiatrists will be working closer with their medical and surgical colleagues. This will mean that these general psychiatrists will be called in to see patients in medical and surgical settings with "liaisontype problems'. These psychiatrists must be aware of the skills needed to handle these problems, even if they only occasionally arise. If they handle the referral inappropriately it is likely to encourage the continuation of the criticisms that many physicians have of psychiatrists. I would like, therefore, to suggest that psychiatric training does devote more time to the teaching and development of certain liaison skills, as there is evidence to suggest that at present most schemes are lacking in this respect. 1

Professor Guz expressed a concern as to whether liaison psychiatrists were able to help in the area of physical symptomatology and depression; both when depression was the cause of physical complaints or when depression was the consequence of physical illness. Physicians sometimes felt that treatment of the depression often did not result in the removal of any associated physical symptomatology. In my experience, if depression is the correct primary diagnosis then pharmacological or psychotherapeutic intervention will usually relieve the physical aches and pains that are commonly present in such patients. In many cases physicians make a diagnosis of depression and are then upset when antidepressants do not take away physical symptomatology. In a number of these cases I feel that the primary diagnosis is not of depression, but perhaps of anxiety or hysteria, when obviously antidepressant therapies will be to no avail. In the other situation when depression is the result of a physical illness, again I personally believe that if the patient is cured and believes himself to be cured of the physical illness, then the depression is likely to lift. In some cases of serious and chronic illness the physician may feel the patient is cured or under control, but the patient himself still has to live with the often realistic fear that the illness may recur. If this fear is not resolved then it is likely that the depression will remain in the presence of apparently cured physical disease.

I was disappointed to hear that physicians feel liaison psychiatrists are not interested in patients with alcohol problems 
and those who have sustained brain damage. Patients with physical problems from alcohol abuse would seem to be an obvious area for liaison psychiatry, and if this is a deficiency then we must try to remedy it. As regards the brain damaged patient, there are, I feel, reasons for a lack of interest. These patients usually require considerable expenditure in both time and personnel and cannot be properly catered for in most psychiatric units. The behavioural problems they exhibit make it difficult for them to be cared for in medical wards and the physical handicaps that are present make for difficulties in psychiatric units. There is a great need for money from central funding to be devoted to the development of specialized units specifically designed for the needs of the brain damaged where both physicians and psychiatrists can work together.

Physicians also appear to be concerned over postulated 'mechanisms' in psychosomatics. Epidemiological research is showing possible relationships between psychological factors and physical disease but as yet the actual mechanistic links are poorly understood. Until further research in this field has been carried out it is probably unwise to make only partly justified speculations on the exact links between psyche and soma. Nevertheless the epidemiological findings still stand and offer therapeutic possibilities. When Sir Richard Doll found the link between smoking and lung cancer it was possible to prevent further disease before the exact nature of the carcinogens and their effect on bronchial mucosa was known. Similarly, the exact link between Type A behaviour and coronaries is not fully established, but if more deaths from heart disease can be reduced by changing the behaviour of Type $A$ subjects then this must surely be a significant advance.

In conclusion I feel properly practised liaison psychiatry may well be useful to medicine. However, if we wish the nature of the service we offer to be acceptable then considerably more discussion between psychiatrists and physicians needs to take place.

RefERENCE

'THomas, C. J. (1985) Teaching and experience of liaison psychiatry in psychiatric postgraduates (Correspondence). Bulletin of the Royal College of Psychiatrists, 9, 81-82.

\section{The Sandoz Prize for Gerontological Research}

The International Association of Gerontology (IAG) has awarded the 1985 Sandoz Prize jointly to Sir Martin Roth, Professor of Psychiatry at the University of Cambridge Medical School, and Dr Karl Esser, Professor of Botany at the University of the Ruhr in Bochum (FRG). The award to Sir Martin Roth is a tribute to the work through which he and his team have made a fundamental contribution to psychogeriatric research over many years, creating a foundation for the study of dementia and depression in old age. Professor Esser has been honoured for the genetic and biochemical work of his team, culminating in the development of new models of the ageing process on a molecular basis.

The prize, worth Sw. fr. 20,000 and sponsored by Sandoz, is awarded every second year by the IAG to individuals or teams who have made an outstanding contribution to some aspect of gerontological research.

\section{WHO Programme for Mental Health}

The Department of Psychiatry of the University of Cambridge School of Clinical Medicine has been recognized by the WHO as a National Institution for Research in Mental Disorder of Old Age under its Programme for Mental Health.

\section{'Convulsive Therapy'}

A new quarterly medical journal, Convulsive Therapy, has recently been launched, dedicated to the research and clinical issues in convulsive therapy. Much of the motivation for the journal has come from the surveys and numerous research reports of the Royal College of Psychiatrists and the American Psychiatric Association. The scope of articles includes biologic and sociologic aspects of the treatments, studies of mechanisms, and the ethical and legal concerns which often mark ECT discussions. The editors seek a forum for researchers, students, and practitioners. The inaugural issue was published in April 1985 by Raven Press in New York. Enquiries may be sent to the Editor: Dr Max Fink, State University of New York at Stony Brook, PO Box 457, St James, New York 11780, USA.

\section{3rd AUTP Conference on 'Teaching Dynamic Psychotherapy'}

Following the conferences on 'Teaching Dynamic Psychotherapy' held at University College, Oxford, in 1982 and 1984, the Association of University Teachers of Psychiatry is planning another conference which will be held from 17 to 19 April 1986, again at University College, Oxford. The first conference took a broad overview of the subject and the second concentrated on supervision and issues around personal therapy. Both conferences attracted participants from all over the country and from various professions, all with an interest in training.

Suggestions from both trainers and trainees as to what topics should be included in the 1986 conference and how these might be presented, e.g. lectures, small group activity, panel discussion, demonstrations, would be gratefully received. Offers to contribute to the programme would also be most welcome. Please write to Dr Sidney Bloch, Deparment of Psychotherapy, Warneford Hospital, Oxford OX3 $7 \mathrm{JX}$ in the first instance. Details of the conference will be published in 'Forthcoming Events' at a later stage, but anyone wishing to be placed on the mailing list is asked to write to Dr Bloch.

Mark Aveline SIDNEY BLOCH Conference Organizers 